\title{
EMOCIONES Y SENTIMIENTOS EN LOS PROCESOS DE SOCIALIZACIÓN POLÍTICA: UNA MIRADA DESDE LA HISTORIA DE LA EDUCACIÓN
}

\section{Emotions and Sentiments in the Process of Political Socialization: a Study from the History of Education}

\author{
Miguel Somoza Rodríguez*, Kira Mahamud Angulo** \\ y Heloísa Helena Pimenta Rocha***
}

\section{LA INVESTIGACIÓN SOBRE EMOCIONES Y SENTIMIENTOS}

El estudio de las emociones y los sentimientos se ha convertido en uno de los campos de investigación de mayor desarrollo en las últimas décadas, ${ }^{1}$ con la particularidad añadida de que es un campo necesariamente multidisciplinar: desde la neurobiología, la psicología y la sociología ${ }^{2}$ hasta las concepciones éticas y filosóficas sobre la justicia y el bien común, pasando, por supuesto, por todas las consecuencias y desarrollos que afectan a los procesos de enseñanza y aprendizaje de los seres humanos.

\footnotetext{
${ }^{1}$ Un estudio exhaustivo de la historia de las emociones en Alemania y España es el «Dossier: Historia de las Emociones» de la revista Cuadernos de Historia Contemporánea 36 (2014).

2 También se podría mencionar la contribución de la antropología en la década de los setenta gracias a los trabajos de - por ejemplo- Jean L. Briggs. Ver Jan Plamper, The History of Emotions. An Introduction (Oxford: Oxford University Press, 2015), 90-117.
}

* UNED. Facultad de Educación. Departamento de Historia de la Educación y Educación Comparada Juan del Rosal, 14. 28040 Madrid. España.msomoza@edu.uned.es

** UNED. Facultad de Educación. Departamento de Historia de la Educación y Educación Comparada Juan del Rosal, 14. 28040 Madrid. España. kmahamud@edu.uned.es

*** Universidade Estadual de Campinas. Departamento de Educação, Conhecimento, Linguagem e Arte. Rua Aglair Buratto Villas Boas, 425, 2/52, Vila Bella, Campinas (SP), Brasil, CEP 13087-725. heloisah@unicamp.br

Cómo citar este artículo: Somoza Rodríguez, Miguel; Mahamud Angulo, Kira y Pimenta Rocha, Heloísa H. «Emociones y sentimientos en los procesos de socialización política: una mirada desde la Historia de la Educación», Historia y Memoria de la Educación, 2 (2015): 7-44. 
En la cultura llamada occidental, el papel de las emociones y los sentimientos ha sido, como mínimo, ambiguo. Por un lado, las emociones fueron consideradas, predominantemente, bajo un prisma negativo, como opuestas o, por lo menos, enfrentadas y en conflicto, con la capacidad de emitir juicios racionales fundamentados. En muchas áreas de la actividad humana las emociones fueron casi prácticamente despojadas de cualquier atributo que las relacionara con las capacidades de conocer, analizar, evaluar y decidir atendiendo a criterios de objetividad, sistematicidad, coherencia lógica y pertinencia, es decir, alejadas de las funciones mentales e intelectuales más elevadas. Cuando no eran sentimentalizadas, eran demonizadas o neutralizadas. ${ }^{3}$ Por el contrario, las emociones fueron más bien entendidas como compulsiones biológicas que lastraban la conducta y el comportamiento auténticamente civilizados, ya fuera como penosos resabios del pasado evolutivo, ya como imperfecciones y precariedades del mundo material frente a un mundo espiritual idealizado. En cualquier caso y durante mucho tiempo, frente a las emociones solo cabía dominarlas, constreñirlas o, al menos, apaciguarlas todo lo posible. Durkheim es uno de los defensores de este racionalismo manifestando su preocupación por la interferencia del sentimiento en el pensamiento y en el estudio del hecho social, y por tanto, por la evidencia de una presencia emocional (en forma de pasión) en las inclinaciones políticas, religiosas y morales.

Lo que hace particularmente difícil esta liberación en la sociología es que el sentimiento reclama a menudo su parte. En efecto, nos apasionamos por nuestras creencias políticas y religiosas, por nuestras prácticas morales, mucho más que por las cosas del mundo físico; después, este carácter pasional se comunica a la manera en que concebimos y nos explicamos las primeras. ${ }^{4}$

Por otro lado, aunque quizás en un plano menos enfático y manifiesto, emociones y sentimientos no dejaron de tener sus defensores, y, por supuesto, nunca dejaron de tener un papel activo, destacado y primordial en la evolución política y cultural de la humanidad. En la historia del pensamiento occidental, numerosos autores hoy considerados clásicos se ocuparon

\footnotetext{
${ }^{3}$ Mabel Berezin, «Secure States: towards a political sociology of emotions», en Emotions and Sociology, ed. Jack Barbalet (London: Basil, Blackwell, 2002), 35.

${ }^{4}$ Émile Durkheim, Las reglas del método sociológico (México: Fondo de Cultura Económico, 1997, [1. ${ }^{\mathrm{a}}$ ed. 1894]), 73-74.
} 
del estudio de las emociones, designadas con diferentes nombres según las épocas: apetitos, humores, pasiones.

Platón, que inauguró la postura dualista cuerpo-mente, fue contestado por Aristóteles, quien pensaba, por el contrario, que el cuerpo y la mente formaban una unidad. En el siglo XVII salieron a la luz las obras de conspicuas figuras de la filosofía y la ciencia: René Descartes (Les passions de l'âme) retomó la dualidad cuerpo-alma; Baruch Spinoza reaccionó contra la teoría cartesiana y afirmó que cuerpo y alma están unidos. Inauguró, por su parte, la corriente de pensamiento que atribuyó valor cognoscitivo a las emociones, a las que conceptualizó como «pensamientos confusos». Otros filósofos relevantes que trataron sobre las emociones fueron Blaise Pascal (Discours sur les passions de l'amour), Leibniz y John Locke, quien dedicó el capítulo XX de An Essay Concerning Human Understanding a los modos de placer y dolor, estableciendo que «amamos, deseamos, nos regocijamos y tenemos esperanza, solo respecto del Placer» mientras que «odiamos, tememos y nos afligimos solo respecto del Dolor fundamentalmente». ${ }^{5}$

En el siglo XVIII David Hume clasificó las pasiones en directas e indirectas: las primeras serían sencillas sensaciones de placer o dolor que surgen de la apreciación del mal o del bien, en tanto que las segundas procederían de los mismos principios pero en conjunción con otras cualidades. ${ }^{6} \mathrm{El}$ primer grupo incluiría el deseo, la aversión, la aflicción, la alegría, la esperanza, el miedo, la desesperación y la seguridad mientras que las indirectas comprenderían el orgullo, la humildad, la ambición, la vanidad, el amor, el odio, la envidia, la pena, la malicia y la generosidad. También en ese siglo, Adam Smith publicó The Theory of Moral Sentiments.

En el siglo XIX nos encontramos con la publicación en 1803 de la obra Pedagogía, de Kant, en la que se distingue entre los vicios y las virtudes. Los primeros pueden ser de maldad: envidia, ingratitud y alegría por el mal aje-

\footnotetext{
5 John Locke, An Essay Concerning Human Understanding (Oxford: Oxford University Press, 1990, [1690]), 232. El original dice así: «we love, desire, rejoice, and hope, only in respect of Pleasure» mientras que «we hate, fear, and grieve only in respect of Pain ultimately».

${ }^{6}$ En la segunda parte (Book II) del A Treatise of Human Nature, dedicado a las pasiones: orgullo y humildad; amor y odio, voluntad y pasiones directas. Hemos consultado la segunda edición revisada por P. H. Nidditch de la anteriormente editada por L. A. Selby-Bigge: David Hume, A Treatise of Human Nature (Oxford: Oxford University Press, 1990, 7. ${ }^{\text {a }}$ reimpresión de la 2. a edición de 1978, [1. a edición 1888]), 275-454. La cita original dice así: «By direct passions I understand such as arise immediately from good or evil, from pain or pleasure. By indirect such as proceed from the same principles, but by the conjunction of other qualities», 276-277.
} 
no; de bajeza: injusticia, infidelidad y desorden; o de pusilanimidad: dureza, mezquindad y pereza. Las segundas se agrupan en aquellas de mérito (generosidad, "vencimiento de sí mismo, tanto en la venganza como en el bienestar y en la codicia», la caridad y el dominio de sí mismo); de deber (honradez, decencia y carácter pacífico) o de inocencia (probidad, modestia y sobriedad). ${ }^{7}$ En 1872 salía a la luz la obra de Charles Darwin The Expression of the Emotions in Man and Animal, donde hacía referencia a un conjunto de expresiones emocionales existentes en todos los mamíferos, incluidos los humanos, clasificándolas en «depresoras» (el llanto, la cólera y el asombro) y "estimulantes» (la risa y el contacto, que evoluciona en el ser humano hacia la ternura y el amor). Otras grandes figuras de este siglo, ya a caballo sobre el siglo XX, fueron William James, quien publicó en 1884 su famoso ensayo What is an emotion, y John Dewey, con su The Theory of Emotion, aparecida en 1894, en la que cuestionaba las concepciones de Darwin y de James.

En el siglo XX, Sigmund Freud fue otra de las grandes figuras que se ocupó de las emociones y los sentimientos. Su preocupación principal no fue explicar qué eran las emociones ni su origen (a las que designó como «instintos» o «pulsiones») sino analizar cómo afectaban a la personalidad y al equilibrio psíquico. Una de sus principales aportaciones fue la teoría de la represión, según la cual las emociones reprimidas regresan como patologías. Otra aportación freudiana de utilidad para el estudio del uso sociopolítico de las emociones es el concepto de narcisismo, que fue aplicado ya al estudio del patriotismo o del «orgullo nacional» («narcisismo colectivo»), o también a la caracterización de la cultura contemporánea: la posmodernidad sería la expresión acabada del narcisismo en tanto que «cultura del yo», exaltación del individualismo y de la subjetividad. ${ }^{8}$

\section{LOS PUNTOS DE INFLEXIÓN A FINALES DEL SIGLO XX}

Desde finales del siglo Xx y durante la primera década del presente, el estatus epistemológico de las emociones ha sufrido un vuelco gracias a los avances en varias ciencias que convergen en su objeto de estudio y fusionan

\footnotetext{
${ }^{7}$ Kant, Pedagogía (Madrid: Akal, 1983), 85. Traducción de Lorenzo Luzuriaga y José Luis Pascual. Es obligado aclarar que el libro es la publicación de los apuntes de Friedrich Theodor Rink, alumno de Kant —quien autorizó su publicación- en sus clases de «Pedagogía». Ver Guillermo Bustamante-Zamudio, «Pedagogía de Kant: ¿una filosofía de la educación?», Magis. Revista Internacional de Investigación en Educación 5 (10), (2012): 157.

${ }^{8}$ Christopher Lasch, La cultura del narcisismo (Barcelona: A. Bello, 2000).
} 
sus contribuciones y hallazgos. La psicología, la sociología y la neurociencia permiten extender y exportar sus hallazgos, conceptos teóricos y categorías de análisis generando nuevo conocimiento en sus campos y en otros como la educación, la política, la ética y la filosofía, terrenos en los que las emociones si bien no habían estado ausentes sí estaban en segundo plano, ya fuera en su faceta de elementos constitutivos y organizadores de la psique humana, o como objeto legítimo del conocimiento científico, debido, sobre todo en este último aspecto, al paradigma racionalista dominante.

Dos momentos clave de esta tendencia, que afectan a la educación de forma casi directa, provienen de la psicología: el despegue y punto de inflexión en la investigación psicológica sobre emociones y sentimientos está en la publicación de las Multiple Intelligences de Howard Gardner en 1985. Diez años después de la publicación de la obra de Gardner, salió a la luz

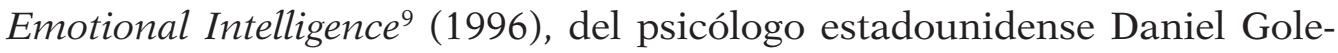
man (quien luego publicó otros libros sobre inteligencia social y ecológica) ${ }^{10}$ Éste último reconoce que reconstruye la «inteligencia emocional» partiendo de los conceptos de Gardner sobre las inteligencias «intrapersonal» (conocimiento y gestión de los aspectos emocionales internos de uno mismo) e «interpersonal» (capacidad de reconocer estados de ánimos de otros, empatía). La idea central de Goleman es que la «inteligencia emocional»se compone de cuatro pilares: conciencia de uno mismo (self-awareness), gestión de nuestras emociones (managing our emotions), empatía (empathy) y habilidades sociales (social skills).

La sociología de las emociones contribuyó también a una nueva conceptualización de los fenómenos como categorías de análisis de hechos, estructuras y dinámicas sociales. Los nuevos enfoques de la macro y micro política fueron liderados por los sociólogos Jack Barbalet ${ }^{11}$ y Thomas Scheff. El primero argumentó que emociones como la vergüenza, el miedo, la venganza y el resentimiento son cruciales para comprender muchos

\footnotetext{
${ }^{9}$ Daniel Goleman, Emotional Intelligence. Why it can matter more than IQ (Londres: Bloomsbury Publishing Plc, 1996).

${ }^{10}$ Social Intelligence: The New Science of Social Relationships (New York: Bantam Dell, 2006) y Ecological Intelligence: How Knowing the Hidden Impacts of What We Buy Can Change Everything (New York: Broadway Books, 2009).

${ }^{11}$ Como autor, Emotion, Social Theory and Social Structure: A Macrosociological Approach (Cambridge: Cambridge University Press, 1998 y 2001) y como editor, Emotions and Sociology (Oxford: Blackwell Publishing, 2002 [Sociological Review Monograph Series]).
} 
procesos sociales y que, por tanto, los conceptos o categorías de emociones pueden ser aplicados en el desarrollo de explicaciones y teorías sociológicas. El sociólogo defiende la existencia de dos tipos de sentido o significado, que aunque convergentes, son también diferentes: el formal y el afectivo. Ambos son necesarios para que la vida social sea posible.

El significado, entendido en términos del orden de referencias, puede referirse tanto a la inteligibilidad y el compromiso. El significado formal explica las relaciones dentro de un todo, lo que hace algo inteligible, mientras que lo que podría llamarse significado afectivo se refiere a la involucración que una persona tiene con un objeto o acontecimiento, es decir, la forma en que les importa. ${ }^{12}$

La propuesta conduce a pensar que el significado o sentido de los objetos, cosas, eventos, personas, etc., no es una propiedad intrínseca de tales objetos, cosas, eventos y personas, sino de las relaciones que se establecen con ellos. ${ }^{13}$ Cuando el significado afectivo falla, se padece el sentimiento del aburrimiento. En definitiva, la presencia y el contenido emocional del significado de la vida social está fuera de toda duda. La clave está en qué significado afectivo otorgamos a los diversos y múltiples componentes de nuestras vidas. Aprendemos a odiar y amar, a sentir orgullo y vergüenza, miedo y valor, a sentirnos felices o desdichados dentro de nuestro contexto socio-educativo. El aprendizaje e incorporación de dichos sentimientos hacia determinadas personas, situaciones u objetos guía nuestros pensamientos y nuestras acciones. Se comprende así que exista un mundo emocional, que los objetos, conceptos y fenómenos adquieran y posean un significado emocional: patria, religión, maternidad, guerra, familia, nación, constituyen una serie de elementos cargados de emociones intensas, llenas de significado y valor.

El sociólogo americano Thomas Scheff, profesor emérito de sociología en la Universidad de California, publicó en 1990 Microsociology. Discourse, Emotion, and Social Structure, estableciendo que los valores son creencias con carga emocional, que las emociones son una fuerza poderosa en la estructura

\footnotetext{
12 Jack Barbalet, «Boredom and social meaning», British Journal of Sociology 50 (4), (1999): 632. La cita en el original dice así: «Meaning, understood in terms of the ordering of references, can relate to both intelligibility and involvement. Formal meaning explicates relationships within a whole, thus making something intelligible, whereas what might be called affective meaning relates to what involvement a person has with an object or event, that is, how it matters to them».
}

13 Barbalet, «Boredom and social meaning», 631. 
y el cambio de las sociedades. Argumenta que la vergüenza, que abarca toda una amplia gama de emociones, es la emoción social más importante, la emoción social por excelencia, la emoción clave para entender la vida social y las relaciones sociales. ${ }^{14}$ Junto a la vergüenza, el orgullo, su opuesto, constituyen las dos emociones básicas que rigen la balanza de la vida social.

Barbalet afirma que el interés de la sociología por la emociones renace con una obra clásica de la sociología en Estados Unidos, Conflict Sociology. Toward an Explanatory Science (1975), ${ }^{15}$ de Randall Collins, quien sugirió que muchos de los conceptos de la teoría sociológica clásica, como «solidaridad», «valores», «conflictos», «legitimidad» y «estatus», hacen referencia implícita a procesos emocionales y que, por tanto, un enfoque más directo sobre las emociones mejoraría nuestra comprensión del mundo social. La propuesta teórica más importante de este autor es discutir y cuestionar la idea de que la emoción sea principalmente una consecuencia de procesos culturales y cognitivos, en lugar de procesos socio-estructurales y relacionales. Duda de la exclusiva construcción social de la emoción y apunta hacia una construcción socio-estructural de la misma.

Entre los estudiosos españoles actuales que se aproximaron a estos temas con enfoques renovados a finales del siglo pasado se pueden citar a varios científicos de diversas disciplinas, hecho que constata el interés suscitado en España desde distintos campos de investigación. El antropólogo José Antonio Jáuregui publicó en 1990 El ordenador cerebral con el siguiente subtítulo: «Un análisis del cerebro como un ordenador que indica y ordena al individuo qué debe hacer para que funcione su cuerpo y su sociedad mediante el disparo de mecanismos emocionales». La publicación del libro en su versión inglesa llevó por título The Emotional Computer (1995). ${ }^{16}$ José Antonio Marina también escribe sobre emociones y sentimientos desde los años noventa. ${ }^{17}$

\footnotetext{
14 Thomas Scheff, "Shame and the Social Bond: A Sociological Theory», Sociological Theory 18 (1), (2000) y Thomas Scheff y Suzanne M. Retzinger, «Shame as the Master Emotion of Everyday Life», Journal of Mundane Behavior 1 (3), (2000).

15 Este clásico de la sociología ha sido revisado y actualizado por el editor Stephen K. Sanderson, Conflict Sociology. A Sociological Classic Update, by Randall Collins (Boulder: Paradigm Publishers, Series: Studies in Comparative Social Science, 2010).

${ }^{16}$ El ordenador cerebral (Barcelona: Labor, 1990); The Emotional Computer (Oxford: Blackwell Publishers, 1995).

${ }^{17}$ El Laberinto Sentimental (Barcelona: Anagrama, 1996) y Diccionario de los Sentimientos (Barcelona: Anagrama, 1999).
} 


\section{DISTINCIÓN ENTRE EMOCIÓN Y SENTIMIENTO}

La consolidación de la investigación multidisciplinar ha tenido lugar en el siglo XXI. La neurociencia abrió una puerta a la divulgación científica con El error de Descartes (1994), del neurobiólogo de origen portugués Antonio Damasio, estableciendo la distinción entre los términos que hasta entonces -y aún ahora - se venían empleando de manera equivalente e intercambiable: emociones y sentimientos.

Según Damasio, las emociones proporcionan un medio natural para que el cerebro y la mente evalúen el ambiente exterior que rodea al organismo y para que respondan en consecuencia y de manera adaptativa: «el aparato de las emociones evalúa de forma natural, y el aparato de la mente consciente coevalúa racionalmente». ${ }^{18}$ Es necesario ratificar, por tanto, que emociones y sentimientos no son términos equivalentes. Mientras las primeras ocurren en el escenario del cuerpo (aumento de la tensión sanguínea y del ritmo cardíaco; subida del umbral de dolor, dilatación de los vasos capilares, etc.) los segundos se manifiestan sobre todo en la mente y serían ellos, precisamente, quienes la habrían fundado, a través del condicionamiento de procesos intelectuales fundamentales como la atención, la memoria y la toma de decisiones. Si las emociones son cambios en el estado del cuerpo como reacciones a los cambios del medio ambiente, natural o social, los sentimientos serían la conciencia de la experiencia de esos cambios. Traducirían el estado de la vida biológica al lenguaje de la mente y del intelecto. El paso de la emoción al sentimiento es automático y de ahí su frecuente (aunque erróneo) uso como sinónimos.

Las emociones formarían parte de los mecanismos básicos de regulación de la vida en tanto son repertorios o protocolos de reacciones automáticas que promueven la supervivencia de un organismo. Este dispositivo permitió a los organismos simples responder de forma efectiva pero no creativa a las variaciones del medio en el que desenvuelven su vida, partiendo de las conductas básicas de aceptar o rechazar, acercar o alejar elementos del medio natural según fuesen positivos o negativos para los procesos vitales. El aumento de complejidad de las formas de vida introdujo un segundo dispositivo regulatorio: los sentimientos, es decir, la interposición de una

${ }_{18}$ Antonio Damasio, En busca de Spinoza. Neurobiología de la emoción y los sentimientos (Barcelona: Crítica, 2005), 67. 
alerta mental entre los estímulos buenos o malos del medio, con la cual la respuesta automática resultaba mediada por una segunda instancia que también evaluaba y regulaba a la primera, vinculando los sentimientos con la reflexión y el pensamiento.

En líneas generales, Damasio viene a decir que las zonas en las que está dividido el cerebro están separadas anatómicamente pero no funcionalmente: son interdependientes. Las emociones son cambios en el estado del cuerpo, controlado por el sistema cerebral, que responden a estímulos relevantes ( «objeto emocionalmente competente», ${ }^{19}$ empleando su terminología). Los sentimientos son la conciencia de esos cambios, la percepción, idea o pensamiento de un cambio o de un estado particular del cuerpo. Son pensamientos específicos, no cualesquiera, que representan el cuerpo en un proceso reactivo. Emociones y sentimientos desempeñan un papel decisivo en el comportamiento social. Las respuestas emocionales pueden, por lo tanto, ser moduladas, y es aquí donde se muestra la estrecha conexión entre emociones, sentimientos y procesos socializadores, en tanto que uno de los objetivos fundamentales del desarrollo educativo es interponer un paso evaluativo no automático entre los objetos o circunstancias causales y las respuestas emocionales para adecuarlas a los requerimientos de una cultura determinada. ${ }^{20}$

En España, varios autores contribuyeron al desarrollo de la investigación desde sus diversos campos de estudio. José Antonio Marina ofreció otros libros sobre el tema. ${ }^{21}$ Carlos Castilla del Pino, desde la psiquiatría, publicó en el año 2000 su Teoría de los sentimientos (que no de las emociones), re-examinando a los clásicos, analizando emociones concretas y ciertas patologías, criticando a Antonio Damasio (por no haber entendido a Descartes y atribuirle un dualismo de naturaleza, en lugar de un dualismo formal o funcional), profundizando en la expresión verbal del mundo afectivo de las personas, estableciendo la existencia de una gramática cognitiva y otra gramática afectiva, y proponiendo su explicación sobre el odio y su teoría de los metasentimientos. Los metasentimientos aluden a la concien-

\footnotetext{
19 Damasio, En busca de Spinoza, 106.

20 Damasio, En busca de Spinoza.

${ }^{21}$ Anatomía del miedo: Un tratado sobre la valentía (Madrid: Anagrama, 2006); La educación del talento (2010); Los secretos de la motivación (Barceloma: Ariel, 2011) y El cerebro infantil: la gran oportunidad (Barcelona: Ariel, 2011).
} 
cia de la doble vida de todo ser humano, la íntima y personal, por un lado, y la pública y social, por otro. Los niños van aprendiendo sobre la existencia y el manejo de esa doble vida o de ese doble «yo» que poseen.

Otras relevantes figuras españolas dedicadas al estudio de las emociones, desde diferentes perspectivas académicas, son Ignacio Morgado, ${ }^{22} \mathrm{ca}$ tedrático de Psicobiología, y Victoria Camps, catedrática de Filosofía Moral y Política, quienes trabajan en la Universidad Autónoma de Barcelona. En El gobierno de las emociones, Camps analiza cual es el lugar de las emociones en la ética, partiendo de la hipótesis de que no hay razón práctica sin sentimientos, pues no basta conocer el bien: hay que desearlo para poder practicarlo. "El deseo y el desprecio, el gusto y el disgusto son tan esenciales para la fomación de la personalidad moral como lo es la destreza en el razonamiento». ${ }^{23}$ Adela Cortina, catedrática de Ética y Filosofía Política en la Universidad de Valencia, por otra parte, escribió Neuroética y neuropolítica. Sugerencias para la educación moral, ${ }^{24}$ donde se pregunta sobre el papel que cumple el cerebro y sus circuitos neuronales en la configuración ética y moral de las personas y como estas configuraciones influyen, a su vez, en el campo de la política y en la estructuración y regulación de la sociedad, asignándole a la educación, y a la educación cívica en particular, una función principal en la aceptación de la dignidad universal del ser humano y de sus inviolables derechos. ${ }^{25}$

\section{LAS EMOCIONES EN LA LITERATURA Y EL ARTE}

Una manifestación de la atracción que las emociones suscitan puede ser encontrada en las esferas artísticas, ya literarias, audiovisuales o gráficas. En estos campos de la creatividad humana las emociones y los sentimientos no solo están legitimados para expresarse extensamente, sino que son uno de los principales objetos de interés de sus variadas formas expresivas. En el

\footnotetext{
${ }^{22}$ Emociones e Inteligencia Social: Las claves para una alianza entre los sentimientos y la razón (Barcelona, Ariel, 2007) y Cómo percibimos el mundo. Una exploración de la mente y los sentidos (Barcelona: Ariel, 2012).

${ }^{23}$ Victoria Camps, El gobierno de las emociones (Barcelona: Herder, 2011).

${ }^{24}$ Adela Cortina, Neuroética y neuropolítica. Sugerencias para la educación moral (Madrid: Tecnos, 2011).

${ }_{25}$ Para una información más detallada sobre los avances en la investigación sobre emociones y sentimientos en relación a la ética, la política y la sociología ver: Kira Mahamud, «Emociones y sentimientos: coordenadas históricas y multidisciplinares de un campo de estudio clave para las ciencias de la educación", Avances en supervisión educativa, 16 (2012). Disponible en: http://www.adide.org/revista/index. php?option=com_content\&task=view\&id=446\&Itemid=72 (consultado el 17/09/2015).
} 
caso español (y luego con profunda influencia sobre otros países), el género de la novela moderna se funda sobre la «locura», el desarreglo emocional y el análisis psicológico en profundidad de un —en apariencia- ordinario y anodino personaje, pero cabalmente representativo de la compleja naturaleza emocional humana. Prácticamente lo mismo se podría decir de casi cualquier gran obra literaria de los últimos siglos.

Un ejemplo diferente lo hallamos en la novela de George Orwell, 1984. El autor destaca la relevancia de las emociones y de los sentimientos en la sociedad a través de instituciones como el Ministerio del Amor y de rituales como los «dos minutos de odio». El primero es, además y a pesar de la existencia de la "policía del pensamiento», el ministerio encargado de mantener la ley y el orden, y la institución más temida. El acto de los «dos minutos de odio» frente al programa televisivo posee similitudes con cualquier evento colectivo conmemorativo o liturgia, con la diferencia de tener el propósito de hacer experimentar y manifestar otros sentimientos, en este caso, el odio al enemigo. A través del protagonista, Orwell describe al detalle la experiencia de los dos minutos de odio como un rito colectivo de abducción emocional.

Lo horrible de los Dos Minutos de Odio no era el que cada uno tuviera que desempeñar allí un papel sino, al contrario, que era absolutamente imposible evitar la participación porque era uno arrastrado irremisiblemente. A los treinta segundos no hacía falta fingir. Un éxtasis de miedo y venganza, un deseo de matar, de torturar, de aplastar rostros con un martillo, parecían recorrer a todos los presentes como una corriente eléctrica convirtiéndole a uno, incluso contra su voluntad, en un loco gesticulador y vociferante. Y sin embargo, la rabia que se sentía era una emoción abstracta e indirecta que podía aplicarse a uno u otro objeto como la llama de una lámpara de soldadura autógena. ${ }^{26}$

La ficción especulativa de Orwell no se aleja demasiado de ciertas realidades. Su perspicaz, aunque pesimista, análisis de la posible evolución política de las sociedades incluye las emociones y los sentimientos como elementos que desempeñan un papel esencial en los procesos y estructuras sociales.

${ }^{26}$ George Orwell. 1984. Segunda Edición Electrónica de 2014. http://www.lanuevaeditorialvirtual.blogspot.com.ar/ (consultado el 17/09/2015). 
La poesía, por su parte, adoptando los versos de Wordsworth, «es el rebosar espontáneo de emociones poderosas; tiene su origen en la emoción recogida en tranquilidad». ${ }^{27}$ Esta afirmación del poeta nos sirve para traer a colación tres cuestiones. La primera apunta hacia lo que venimos diciendo sobre la expresión de emociones en la creación artística, la segunda matiza el hecho de tratarse de emociones y sentimientos libres y auténticos que brotan del interior del individuo, distanciándose de aquellos impuestos desde arriba, recomendados, sugeridos por la sociedad o la educación. Éstos últimos son los que predominantemente estudiamos en este monográfico pues la Historia de la Educación nos enseña que las emociones y los sentimientos considerados adecuados en cada momento histórico y necesarios para el funcionamiento de la sociedad en dicho momento, son los que se inculcan, proyectan, transmiten, enseñan, recomiendan o imponen. La tercera tiene en cuenta el uso didáctico y educativo que tienen las artes, para transmitir conocimiento y emoción. ${ }^{28}$

El vehículo de expresión de la literatura y la poesía es la palabra, el lenguaje y dentro del mismo, el instrumento fundamental es la metáfora como vía de expresión y creación de emociones y sentimientos. La metáfora puede tener varios usos: político (al servicio de ideologías), ${ }^{29}$

\footnotetext{
27 William Wordsworth, Preface to Lyrical Ballads, 1801, 26. http://www.bartleby.com/39/36.html (consultado el 17/09/2015). La cita original dice así: «Poetry is the spontaneous overflow of powerful feelings; It takes its origin from emotion recollected in tranquility». Cristina Flores Moreno explica esta «teoría» de la siguiente manera: «la poesía surge a partir de la explosión de sentimientos producidos ante la recreación tranquila de recuerdos de emociones pasadas». Ver Cristina Flores Moreno, "Solo recuerdo la emoción de las cosas": ecos de la poética de William Wordsworth en Antonio Machado", Odisea, 14 (2013): 73.

${ }^{28}$ Ver Carole Cox, «Literary Education: education of the emotions or indoctrination», Westminster Studies in Education 9 (1), (1986): 67-74.

${ }^{29}$ Los modelos de pensamiento enmarcan los temas y asuntos que se están tratando, reducen la materia a determinados elementos constituyentes, edifican fronteras y bloquean o impiden que se tengan en cuenta otros elementos o características. Dirigen y concentran la atención hacia elementos previamente seleccionados. Las metáforas son, en definitiva, aliadas de la ideología y necesarias para su propagación. Lakoff y Johnson expresan esta idea de otra manera, afirmando que las ideologías políticas están enmarcadas en términos metafóricos. Ver George Lakoff y Mark Johnson, Metaphors We Live By (Chicago: University of Chicago Press, 1980), 236. No es casualidad que durante el nazismo, según narra el filólogo Victor Klemperer, se recurriera a la metáfora técnica, a través de la cual las personas eran comparadas con motores y máquinas. La tendencia a la mecanización y automatización de la vida era un hecho y ello, lamenta el autor, revelaba una mentalidad desespiritualizada. Ver Victor Klemperer. LTI. La lengua del Tercer Reich. Apuntes de un filólogo (Barcelona: Editorial Minúscula, 2001), 217-230. Cyrulnik también aborda esta cuestión en una sección titulada «Los fabricantes de vergüenza y su camuflaje lingüístico» en Boris Cyrulnik, Morirse de vergüenza. El miedo a la mirada del otro (Barcelona: Debate, 2011), 158-160.
} 
didáctico ${ }^{30}$ y creativo/liberalizador. Escolano nos dice en su último libro La España cubista de Luis Bello que

el lenguaje era para el cronista de El Sol no sólo un instrumento de comunicación sino un medio de hacer política, y de hacer pedagogía, muy especialmente en aquellos años en los que la libertad de expresión estaba constreñida por la censura dictatorial. Mediante la metáfora, al igual que con el aguafuerte literario y otros gestos semióticos, incluidos los del lenguaje gráfico y plástico, se podía abrir paso la libertad acorralada. Ella, la metáfora, era una fuente de creatividad intelectual y un recurso para el análisis más sincero y moral de los problemas de España. ${ }^{31}$

La literatura contemporánea de ciencia ficción y el cine también ofrecen un curioso testimonio de la ambigüedad cultural respecto a emociones y sentimientos. En muchas de sus obras los ordenadores o los robots humanoides provistos de portentosa inteligencia digital (mecánica, después de todo) alcanzan su máxima expresión de desarrollo (más allá de la inmensa memoria y de la potencia de procesamiento) cuando son capaces de tener sentimientos: se hacen «humanos» (o más que humanos) al alcanzar la capacidad de experimentar emociones. En la novela de Arthur C. Clarke y luego en la película de Stanley Kubric, 2001: Odisea del espacio (1968), el ordenador Hal 9000 llega a pensar por sí mismo, y siente miedo. La capacidad de experimentar emociones, empatía en primer lugar, juega un papel central en la también extraordinaria Blade Runner (1982), con sus avanzados androides Nexus-6, en la que el contraste entre el «replicante» androide Roy Batty y el detective Rick Degard, señala la paradoja de quien, a pesar de

\footnotetext{
${ }^{30}$ Hung Ng y Bradac argumentan que las metáforas son modelos de pensamiento sobre objetos sociales y físicos que sirven para comunicar grupos complejos de atributos en forma abreviada que puedan ser rápidamente comprendidos. Ver Sik Hung Ng y James J. Bradac, Power in language. Verbal Communication and Social Influence (London: Sage Publications, 1993), 138. Hugh G. y Rebecca Oshlag también han comprobado que las metáforas son útiles en el proceso de enseñanza-aprendizaje, es decir, pueden servir al profesor y al alumno. Ver Hugh G. Petrie y Rebecca S. Oshlag, «Metaphor and Learning», en Metaphor and Thought, ed. Andrew Ortony (Cambridge: Cambridge University Press, 1993), 579-609. Esto se explica porque el lenguaje figurativo y los tropos constituyen estrategias lingüísticas que también reflejan esquemas poéticos para conceptualizar la experiencia humana y el mundo exterior guiando nuestros sentimientos, acciones y reacciones ante el mismo. Ver Raymond W. J. R. Gibbs, «Process and products in making sense of tropes», en Metaphor and Thought, ed. Andrew Ortony (Cambridge: Cambridge University Press, 1993), 269.

${ }^{31}$ Agustín Escolano Benito, La España cubista de Luis Bello. Visiones desde la escuela (Valladolid, Madrid: Universidad de Valladolid, UNED, 2014), 17.
} 
su naturaleza emocional humana, actúa sin conciencia ni compasión ejecutando («retirando») androides. Yo, Robot (2004), dirigida por Alex Proyas, también indaga sobre la posibilidad de construir robots que sueñen, tengan sentimientos y se rebelen contra sus creadores. Más adelante, en el año 2008 pudimos disfrutar de $W A L L \cdot E$, dirigida por Andrew Stanton. Uno de los robots instalados en el abandonado planeta Tierra continua su labor de limpieza, aunque coleccionando de forma selectiva y emotiva objetos que encuentra durante su jornada, incluida una planta que cuida. Se enamora de la robot EVA cuando la conoce explorando el planeta en busca de señales de vida. Los productores son los mismos que han estrenado recientemente Del revés (Inside Out) (2015). Esta última película de animación trata directamente el tema de las emociones creando personajes para cada una de las cinco emociones básicas que aparecen y que trabajan en equipo dentro del cerebro de la protagonista de la historia: alegría, tristeza, miedo, ira y asco. Las emociones personificadas son las encargadas de ir dirigiendo sus pasos y decisiones, así como de ordenar su recuerdos y almacenarlos en la memoria a largo plazo asociada a ellas.

Estas obras cinematográficas parecen proyectar la íntima perplejidad y la firme sospecha de que las emociones son, por un lado, elementos fundadores de la naturaleza humana en tanto no es posible la autoconciencia sin ellas y, por el otro, el estadio más alto esperable de la perfección tecnológica; en definitiva, que las emociones son inteligencia. Aunque punto de partida en un caso y objetivo final en el otro, estas obras parecen decirnos que el aparato emocional, del que los humanos venimos dotados naturalmente y al que hemos denostado durante mucho tiempo, sería la última frontera de la inteligencia tecnológica. Antropocentrismo, sin duda, pero también expresión de lo que consideramos irrenunciable en el concepto de «humanidad».

La religión, el deporte y el marketing son, por otra parte, ámbitos donde la expresión pública y social de las emociones no solo es considerada una acción o conducta legítima sino que, además, se fomenta y se promueve. Las dos últimas emplean además la publicidad como instrumento de promoción.

\section{LAS EMOCIONES EN LA POLÍTICA}

En el ámbito de la política ocurren cosas más complejas (la propaganda, por ejemplo) y las emociones han entrado a formar parte de los estudios de 
la sociología política ${ }^{32}$ y de la ciencia política para comprender el comportamiento político, ${ }^{33}$ como demuestra la investigación de George E. Marcus. ${ }^{34}$ En la cultura política de la Modernidad se considera, por una parte, que la «decisión racional» es la mayor virtud deseable, es decir, la capacidad del ciudadano (y del dirigente) para tomar decisiones de manera objetiva, racional, fría, distanciada, desapasionada. Y esta virtud política tenía en los varones su depositario y arquetipo principal. Los conceptos de «personalidad racional» y de "personalidad emotiva» no fueron solo figuras retóricas sino construcciones culturales y políticas que otorgaban o denegaban derechos y atribuciones. Las mujeres fueron equiparadas durante décadas a los niños, a los dementes, a los irresponsables, a los incapacitados, por su -se decía- marcado temperamento emotivo que nublaba la razón. Pero también los varones obreros y trabajadores manuales, los pobres y marginados en general, fueron incluidos en esta categoría: la masa, el vulgo, la turba, la muchedumbre irracional.

Sobre todo tras la insurrección popular de París en 1871 (la Comuna de París), el conservadurismo político organizó un discurso teórico y académico sustentado en las entonces recientes teorías psicológicas del hipnotismo y la sugestión mental, que otorgaba la racionalidad al individuo y la pulsión emotiva, irracional y destructiva, a lo grupal y colectivo. Tal como propone Ernesto Laclau en La razón populista ${ }^{35}$ la idea de la irracionalidad de las masas es desarrollada por Hippolyte Taine en Los orígenes de la Francia contemporánea (5 volúmenes, publicados entre 1875 y 1893), asimilando éstas a una invasión de bárbaros mediante la violencia y el terror, y comparando su comportamiento con formas inferiores de vida: «en toda insurrección importante hallamos los mismos actores malignos y vagabundos, enemigos

\footnotetext{
${ }^{32}$ Los estudios de Berezin tienen gran relevancia para la educación y la socialización política pues manejan los conceptos de Estado seguro (secure state) y comunidad de sentimiento (community of feeling). Ver Berezin, «Secure States: towards a political sociology of emotions».

${ }^{33}$ Eric Groenendyk, "Current Emotion Research in Political Science: How Emotions Help Democracy Overcome its Collective Action Problem», Emotion Review 3 (4), (2011): 455-463.

${ }^{34}$ George E. Marcus, W. Russell Neuman y Michael MacKuen, Affective Intelligence and Political Judgment (Chicago: University of Chicago Press, 2000); George E. Marcus, The Sentimental Citizen: Emotion in Democratic Politics (University Park: Penn State University Press, 2000); George E. Marcus, «Emotions in Politics», Annual Review of Political Science 3 (1), (2000): 221-50; George E. Marcus, «The Psychology of Emotion and Politics», en Oxford Handbook of Political Psychology, eds. Leonie Huddy, David Sears y Robert Jervis (Oxford: Oxford University Press, 2003): 182-221; W. Russell Neuman et al., The Affect Effect: Dynamics of Emotion in Political Thinking and Behavior (Chicago: University of Chicago Press, 2007).

${ }^{35}$ Ernesto Laclau, La razón populista (Buenos Aires: FCE, 2005).
} 
de la ley, salvajes, merodeadores desesperados, quienes, como lobos, rondan allí donde olfatean una presa». ${ }^{36} \mathrm{El}$ peligro de esta infección era mayor en las clases populares que en las aristocracias, y las mujeres y los niños eran más propensas a ella que los hombres, ideas que dominaban el imaginario social de la época y con las cuales se equiparaba, por definición, el comportamiento de las multitudes con la conducta patológica.

Poco después Gustave Le Bon publicaba Psicología de las masas (1896), libro que reforzaba la idea de que el comportamiento de las masas formaba parte del campo de lo patológico y que ello constituía un rasgo permanente de las sociedades modernas:

Las ideas, sentimientos, emociones y creencias poseen en las masas un poder contagioso tan intenso como el de los microbios [...] en el caso de los hombres reunidos en multitud, todas las emociones se contagian rápidamente, lo cual explica lo repentino del pánico. Los desórdenes mentales, como la locura, son también contagiosos. ${ }^{37}$

También insistía en la inferioridad congénita de la capacidad de pensar de las masas: «El razonamiento inferior de las multitudes [...] una cadena de argumentación lógica es totalmente incomprensible para las multitudes, y por este motivo se puede decir que no razonan o que razonan erróneamente, y que no son influidas por el razonamiento». ${ }^{38}$

A pesar de esta adjudicación arbitraria de razón y emociones, de virtudes y vicios, a las élites y a las multitudes respectivamente, tanto los dirigentes fascistas, ${ }^{39}$ aquellos otros con aspiraciones autoritarias o totalitarias, ${ }^{40}$ como los aristocráticos y liberales de los Estados europeos y americanos no

\footnotetext{
${ }^{36}$ Citado por Laclau, La razón populista, 49. La obra de Taine se puede consultar en http://www.gutenberg.org/files/2578/2578-h/2578-h.htm (consultado el 17/09/2015).

${ }^{37}$ Gustave Le Bon, Psicología de las masas. Disponible en http://www.antorcha.net/biblioteca_virtual/ filosofia/lebon/indice.html (consultado el 17/09/2015).

${ }^{38}$ Le Bon, Psicología de las masas.

${ }^{39}$ Simonetta Falasca Zamponi, «Ecstatic Crowds, Addicted Dictators, Intoxicating Politics: Reflections on Rausch and Fascist Italy», Serie Working Papers, UCLA Center for European and Eurasian Studies, UCLA International Institute, 2004. Disponible en https://escholarship.org/uc/item/67w279nj (consultado el 17/09/2015).

${ }^{40}$ Malte Rolf matiza las diversas formas de expresión emocional del entusiasmo de las masas en la Unión Soviética y la Alemania nazi. Ver Malte Rolf, «Expression of Enthusiasm and Emotional Coding in Dictatorship - The Stalinist Soviet Union», Serie Working Papers, UCLA Center for European and Eurasian Studies, UCLA International Institute, 2004. Disponible en http://eprints.cdlib.org/uc/item/6qh736hj. (consultado el 17/09/2015).
} 
dejaron de utilizar de modo intencional las emociones y los sentimientos para la creación de «comunidades imaginadas» (las naciones y los Estados nacionales), generando al mismo tiempo las doctrinas de legitimación necesarias (el nacionalismo y el patriotismo, entre otras). Refinando el argumento y atendiendo a que la existencia de grupos, asociaciones, públicos, es constitutiva de cualquier sociedad y de cualquier organización política, los pensadores decimonónicos hicieron la distinción entre «comunidades de odio» y "comunidades de amor». ${ }^{41}$ Como es sabido, los sistemas escolares, el currículum y los libros de texto desempeñaron un papel central en estos procesos de difusión de ideologías, de construcción de comunidades políticas más o menos contingentes, y de los Estados nacionales.

Como ejemplos de recepción, adaptación y reelaboración de estas ideas en otros países podemos mencionar a José María Ramos Mejía en Argentina (Las multitudes argentinas, 1899) y José Ortega y Gasset en España ( $L a$ rebelión de las masas, 1929). Este último afirmaba que

en una buena ordenación de las cosas públicas, la masa es lo que no actúa por sí misma. Tal es su misión. Ha venido al mundo para ser dirigida, influida representada, organizada [...] pero no ha venido al mundo para hacer todo eso por sí. Necesita referir su vida a la instancia superior, constituida por las minorías excelentes [...] Pretender la masa actuar por sí misma es, pues, rebelarse contra su propio destino, y como eso es lo que hace ahora, hablo yo de la rebelión de las masas. ${ }^{42}$

Por su parte, el argentino Ramos Mejía (1849-1914), médico, psiquiatra, académico, político y Presidente del Consejo Nacional de Educación entre otros cargos, escribió que

constituyen los principales núcleos de la multitud: los sensitivos, los neuróticos, los individuos cuyos nervios sólo necesitan que la sensación les roce apenas la superficie, para vibrar en un prolongado gemido de dolor o en la vigorosa impulsividad, que es la característica de todas las muchedumbres. Por eso éstas son impresionables y veleidosas como las mujeres apasionadas, puro inconsciente; fogosas, pero llenas de luz fugaz; amantes ante todo de la sensación violenta, del color vivo, de la música ruidosa, del hombre bello y de

\footnotetext{
41 Gabriel Tarde, La opinión y la multitud (Madrid: Taurus, 1986, [1901]).

42 José Ortega y Gasset, La rebelión de las masas (Madrid: Espasa-Calpe, 1993, [1929]), 161-162.
} 
las grandes estaturas; porque la multitud es sensual, arrebatada y llena de lujuria para el placer de los sentidos. No raciocina, siente. Es poco inteligente, razona mal, pero imagina mucho y deforme. ${ }^{43}$

También los movimientos sociales de los años sesenta despertaron suspicacias y críticas por parte de algunos estudiosos, ${ }^{44}$ puesto que

Hasta bien entrado el siglo Xx, las multitudes y sus dinámicas se concibieron como el corazón de los movimientos de protesta. Se asumió que las muchedumbres creaban, a través de la sugestión y el contagio, una especie de sentimientos y mentalidad de grupo psicológicamente "primitivos», compartidos por todos los participantes y fuera de su rango normal de sensibilidad..$^{45}$

El desprecio de las élites hacia los sectores sociales subordinados no es sino una forma literariamente elaborada de expresar, con mayor o menor énfasis, el odio de clase, y podemos encontrarla hasta nuestros días en manifestaciones habituales de las ideologías y formaciones políticas conservadoras, y no solo conservadoras. Owen Jones muestra como los tories británicos y los laboristas de la tercera vía coincidieron y coinciden, en sus dircursos, en menospreciar y culpabilizar a los trabajadores británicos blancos y pobres (la «subclase», a los que denigran con el mote de origen romaní «chavs») de su propia situación, hasta el punto de haberse naturalizado en la prensa, el marketing y en los discursos políticos británicos la imagen de gamberros antisociales, que viven en casas de protección oficial, son incultos y proclives al embarazo adolescente, y se aprovechan maliciosamente de la seguridad social. Así aparecen en una nota del Daily Mail que el autor reproduce:

Mirad a vuestro alrededor, en el autobús y ahora cada vez más en la calle. Encontraréis grupos cada vez más numerosos de tatuados, ruidosos y malhablados proletas seguidos de mugrientos mocosos, que son incapaces de responder o incluso reconocer la cortesía más

\footnotetext{
43 José María Ramos Mejía, Las multitudes argentinas (Buenos Aires: Edit. de Belgrano, 1977), 33-34.

${ }^{44}$ Jeff Goodwin, James M. Jasper y Francesca Polletta, «Introduction: Why Emotions Matter», en Passionate Politics. Emotions and Social Movements, eds. Jeff Goodwin, James M. Jasper y Francesca Polletta (Chicago, London: Chicago University Press, 2001), 3.

45 Goodwin, Jasper y Polletta, «Introduction: Why Emotions Matter», 2. La cita en el original dice así: «Well into the twentieth century, crowds and their dynamics were conceived as the heart of protest movements. Crowds were assumed to create, through suggestion and contagion, a kind of psychologically "primitive" group mind and group feelings, shared by all participants and outside their normal range of sensibilities».
} 
básica [...] No tienen valores ni moral y son tan cortos que no pueden redimirse. Es mejor evitarlos. ${ }^{46}$

Años después de los escritos mencionados anteriormente la emoción política se sitúa otra vez en un lugar destacado del escenario institucional y mediático europeo. Ante situaciones crecientes de desigualdad y exclusión, y ante la apatía y la resignación instaladas en buena parte de las ciudadanías, Stéphane Hessel (iIndignaos!, 2010), ${ }^{47}$ excombatiente de la resistencia francesa, prisionero en campos de concentración, embajador de Francia ante la ONU y uno de los redactores de la Declaración Universal de Derechos Humanos de 1948, hizo una llamada a la acción colectiva y democrática en nombre de una emoción razonada y razonable: la indignación cívica.

La prensa española de este año 2015 se hace eco de la creciente indignación social ${ }^{48}$ ante los acontecimientos bochornosos de una corrupción económica ${ }^{49}$ que señala con el dedo a la codicia, el orgullo, la indiferencia y el menosprecio hacia los débiles y necesitados; que advierte de la decadencia política marcada por la ausencia de ética y el exceso de soberbia, y de la incapacidad de los líderes nacionales e internaciones para poner fin a situaciones de injusticia ante la crisis de refugiados. ${ }^{50}$ La política parece emplear nuevas estrategias más emocionales para captar votantes. A juicio del periodista Enric González, «resulta preocupante» que hayamos «decidido, parece, que la política es emoción y sentimiento», donde

la ira, el desprecio hacia el adversario, la hipersensibilidad (¿han notado que cada vez circulan más noticias acerca de los ofendidos que se sienten tales o cuales?), la incapacidad para el diálogo, son, además de la falsedad, los rasgos que definen el debate político, si es que se le puede llamar debate. ${ }^{51}$

\footnotetext{
46 Owen Jones, Chavs. La demonizacion de la clase obrera (Madrid: Capitan Swing, 2013), 20.

47 Stéphane Hessel, Indignez-vous! (Montpellier: Indigène éditions, 2010, [la edición española es de 2011]). ${ }^{48}$ Miguel Ángel Criado, «El 15-M se alimentó de las emociones en Twitter». http://elpais.com/elpais/2015/05/15/ciencia/1431702091_568838.html (consultado el 17/09/2015).

49 Lucía Méndez, «Rato-PP: la culpa y la vergüenza». http://www.elmundo.es/espana/2015/08/17/55d0cd01e2704e03148b4579.html (consultado el 17/09/2015).

${ }^{50}$ Sami Naïr y Javier de Lucas, «La vergüenza del Mediterráneo†»». http://elpais.com/elpais/2015/04/23/opinion/1429793751_390683.html (consultado el 17/09/2015), y Ruth Ferrero Turrión, «¡Vergüenza!». http:// www.elmundo.es/internacional/2015/08/22/55d75810268e3eea578b4595.html (consultado el 17/09/2015).

${ }^{51}$ Enric Gonzalez, «Emoción». http://www.elmundo.es/opinion/2015/07/25/55b27b74268e3ee17c8b45b3. html (consultado el17/09/2015).
} 


\section{EMOCIONES Y SENTIMIENTOS SOCIALES}

Existe cierto acuerdo entre los científicos en aceptar la clasificación de las emociones en básicas o innatas (la alegría, la tristeza, el miedo, la ira, la sorpresa y la repugnancia) y secundarias, también llamadas cognoscitivas superiores o emociones sociales (amor, culpa, vergüenza, orgullo, odio, envidia, celos, simpatía, empatía, gratitud, indignación, desprecio, etc.).

En La expresión de las emociones en los animales y en el hombre (1872), Charles Darwin postuló la existencia de (además de otras) seis emociones básicas identificables a través del cambio en los rasgos faciales que provocaban. Estas reacciones serían innatas y comunes a todos los seres humanos, e independientes de las singularidades culturales y temporales, tal como expone Stuart Walton en Humanidad. Una historia de las emociones, libro reseñado en esta misma revista. En la década de los sesenta, el psicólogo norteamericano Paul Ekman confirmó los estudios de Darwin a través de varias pruebas de reconocimiento facial mutuo de las emociones básicas entre diferentes culturas y poblaciones humanas (a pesar de que el propósito inicial de Ekman era demostrar precisamente lo contrario, imbuido de las teorías culturalistas predominantes en las ciencias sociales de la época). Por supuesto puede haber pequeñas diferencias culturales en la expresión de las emociones: una cultura puede enfatizar o debilitar las formas públicas de la expresión emocional en general o de alguna emoción básica en particular, sin que se vea afectado el núcleo esencial de las conductas corporales o rasgos faciales implicados en tal emoción. Comparando reacciones ante los mismos estímulos entre grupos de norteamericanos y japoneses (siendo éstos más circunspectos), el propio Ekman descubrió que la expresión inicial de ambos era similar pero que los japoneses la suavizaban en un lapso de décimas de segundo (imperceptible a simple vista) como consecuencia del ajuste cultural.

Para los propósitos de esta presentación es necesario destacar la importancia de las emociones sociales, aquellas que surgen en situaciones interpersonales y provocan acciones o modulan comportamientos con fuertes consecuencias sociales. Las emociones y los sentimientos juegan un papel decisivo en el comportamiento social. Los estudios de Antonio Damasio han demostrado que las personas que sufrieron lesiones en las zonas cerebrales que regulan determinadas clases de emociones y sentimientos ven gravemente perturbada su vida social porque pierden la capacidad de percibir e 
interpretar los contextos interpersonales al mismo tiempo que ven afectada negativamente la capacidad para tomar decisiones, aunque sean nimias. Carecen del sentido de lo que es socialmente apropiado, pero no porque no sean capaces de razonamientos correctos: pueden resolver problemas lógicos, hablan normalmente, pueden obtener una puntuación elevada en los test de cociente intelectual. Sus facultades cognitivas y su intelecto siguen intactos pero el problema radica en el defecto en los procesos de emoción y sentimiento, dado que éstos desempeñan un papel central en la toma de decisiones, que requiere, a su vez, de la memoria (la memoria emocional permite traer a la conciencia recuerdos asociados con experiencias similares) y de la atención consciente y sostenida.

La vergüenza, la culpa, el orgullo o la simpatía son algunas de las emociones sociales más comunes, y cada una de ellas conlleva un conjunto de rasgos fisiológicos, mentales y conductuales más o menos específico. La vergüenza, por ejemplo, "ese sentimiento tóxico, este absceso en el alma», ${ }^{52}$ es consecuencia de una evaluación negativa del yo cuando no se alcanzan ciertos niveles o metas y expresa el conflicto entre el yo y el ideal del yo a través de la disconformidad respecto de nosotros mismos. Provoca confusión mental, torpeza para hablar, interrupción de la acción, se encoge el cuerpo como si quisiera desaparecer o disolverse, se dilatan los vasos capilares y se enrojece la cara, haciendo evidente para los demás el estado de desagrado y debilidad en que nos encontramos. Su base se compone de miedo, tristeza y tendencias sumisas. El orgullo, por el contrario, surge de una evaluación positiva de una acción o capacidad propia. El pecho se expande, el cuerpo se yergue firme, el paso y el gesto se hacen estables y seguros; nos sentimos alegres y llenos de satisfacción, los procesos vitales fluyen con intensidad. Su base es la alegría.

Las emociones sociales son emociones complejas que exigen un cierto y previo desarrollo cognitivo, pues es condición para su manifestación haber desarrollado al menos una noción del yo propio separado de los otros yoes y de los demás objetos. Este tipo de emociones coinciden en un rasgo fundamental: implican una valoración del propio yo, ya sea positiva o negativa, expresan un juicio de valor acerca del estado del yo en el contexto de las interacciones sociales con otros sujetos considerando múltiples aspectos, como los beneficios o perjuicios obtenidos en la interacción; la percep-

52 Boris Cyrulnik, Morirse de vergüenza, 19. 
ción del juicio de valor que muestran los demás acerca de nosotros, como consideración, respeto, desprecio o envidia; un juicio de valor acerca de la pertinencia de nuestras conductas en situaciones específicas (de jerarquía, de protocolo, de clase social, de conocimientos, etc.), una evaluación de nuestras capacidades o limitaciones para ofrecer respuestas adecuadas a las demandas percibidas, etc.

No todas las emociones requieren la misma actividad o procesamiento cognitivo. El ejemplo que nos ofrecen Jeff Goodwin, James M. Jasper y Francesca Polletta resulta irónico y riguroso: no se requiere el mismo nivel de procesamiento cognitivo para temer una sombra que nos acecha que para temer a las políticas de la Organización Mundial del Comercio porque «ciertas emociones dependen de nuestra comprensión de los acontecimientos que ocurren a nuestro alrededor, incluso cuando esa comprensión es inmediata e intuitiva mas que procesada de forma elaborada». ${ }^{33}$ Smith de hecho propone no conceptualizar la estereotipización, el prejuicio y la discriminación como creencias y actitudes, sino como apreciaciones, emociones y acciones de tendencia emocional basadas en la percepción de la identidad social del individuo. ${ }^{54}$

Si emociones y sentimientos juegan un papel central en la identidad y el comportamiento social, y siendo el comportamiento ético parte del social, tienen que ser comprendidos como parte fundamental en la propia configuración del mismo. Si las emociones son juicios de valor, tal como sostiene Marta Nussbaum, no pueden dejarse de lado a la hora de dar cuenta de los juicios y principios valorativos sino, por el contrario, «tendremos que considerar las emociones como parte esencial del sistema de razonamiento ético. No podemos obviarlas razonablemente una vez que reconocemos que las emociones contienen juicios que pueden ser verdaderos o falsos y pautas buenas o malas para las elecciones éticas», ${ }^{55}$ sin que por ello haya que concedérseles una confianza privilegiada o considerarlas inmunes a la

\footnotetext{
${ }^{53}$ Goodwin, Jasper y Polletta, «Introduction: Why Emotions Matter», 13. La cita en el original dice así: "certain emotions depend on our understanding of events around us, even when that understanding is immediate and intuitive rather than elaborately processed».

${ }^{54}$ Eliot R. Smith, «Social Identity and Social Emotions: Toward New Conceptualizations of Prejudice», en D. M. Mackie y D. L. Hamilton, eds. Affect, cognition, and stereotyping: Interactive processes in group perception (San Diego C. A.: Academic Press), 297.

${ }_{55}$ Marta C. Nussbaum, Paisajes del pensamiento. La inteligencia de las emociones (Barcelona: Paidós, 2008), 22.
} 
crítica racional. Por esta razón, en la creación de principios, instituciones y sociedades democráticas el tipo y la calidad de las emociones políticas o públicas juegan un papel de primera importancia, cuestión que constituye el tema central de la reciente obra de Marta Nussbaum Emociones políticas. ¿Por qué el amor es importante para la justicia?, cuya recensión también se incluye en este número.

Aquí hay que recordar el fuerte vínculo existente entre ética y educación por cuanto toda educación (o socialización) trasmite o inculca valoraciones éticas propias de la tradición cultural a la que se pertenece, pero la escuela de una sociedad democrática debe ofrecer, además, un escenario de diálogo, debate y reflexión crítica acerca de esas valoraciones, propiciando el conocimiento de tradiciones y valoraciones diferentes, ya históricas, ya actuales, y ampliando el radio de ejercicio de sentimientos como la compasión, la empatía, la generosidad, la gratitud, el reconocimiento social mutuo desde los círculos íntimos, familiares y similares — donde se suelen manifestar con facilidad—, hacia grupos cada vez más alejados y diferentes — donde se suelen manifestar con creciente dificultad-.

\section{EMOCIONES, SENTIMIENTOS Y SOCIALIZACIÓN POLÍTICA}

Un caso particular de socialización es la socialización política, que se refiere a los procesos por medio de los cuales los miembros de una sociedad aprenden a hacer propios principios, normas, valores, modelos de comportamiento, directa o indirectamente relevantes para los fenómenos políticos. La socialización política puede adquirir formas diversas y se puede distinguir entre socialización política primaria o secundaria, explícita o implícita, directa o indirecta, latente o manifiesta. Para los procesos de escolarización tiene particular importancia la llamada «socialización política secundaria» y manifiesta, que alude a fases más tardías de la misma y que suele realizarse en instituciones, como el sistema escolar, que expresa orientaciones políticas a través del currículum y los libros de texto. ${ }^{56}$

Otro concepto que nos interesa destacar es el de «socialización política indirecta» o latente, que se da cuando existen razones fundamentadas para considerar que tales contenidos indirectos constituyen una premisa

56 Miguel Somoza Rodríguez y Cecilia Pittelli, «Creencia religiosa y socialización política en los manuales escolares del peronismo y del franquismo: un estudio comparado», Historia Caribe 15 (2009): 11-31. 
o un componente para la posterior formación de orientaciones políticas, como por ejemplo, el aprendizaje de actitudes hacia la figura de autoridad en general - padres, maestros, personal religioso, etc.- que, como es probable, resultan transferidas luego a la figura de la autoridad propiamente política. ${ }^{57}$ Dado que no solo la educación formal socializa políticamente - a través de su forma manifiesta, es decir, a través de una explícita transmisión de información, valores y emociones del sistema político-, era necesario contar con la presencia de artículos sobre la educación no formal, que socializa políticamente de forma latente, análoga e incluso inconsciente, transmitiendo información, valores y emociones de otros sistemas sociales como los de la familia, que afectan a las actitudes hacia roles análogos en el sistema político. ${ }^{58}$

La socialización política por medio de la escuela se convirtió en un campo de estudio propio, una subárea en la que se manifestaban las complejas relaciones que han existido siempre entre el sistema político y el sistema escolar. En este sentido, los cultivadores de la sociología política resaltaron la importancia de la educación formal, hasta el punto de que el famoso estudio de Gabriel Almond y Sidney Verba, The Civic Culture, aparecido en 1965, puso un énfasis notable en la educación como una variable importante a la hora de determinar el nacimiento de actitudes políticas. ${ }^{59}$ Pero la socialización política también se realiza a través de la educación informal, del propio sistema político-institucional, la organización y prácticas internas de los partidos políticos y las formas de cooptación política que pueden reforzar o modificar las pautas de la socialización primaria y de la escolar.

Easton y Hess argumentan que «los años verdaderamente formativos del miembro que madura en un sistema político parecen ser las edades entre tres y trece». ${ }^{60} \mathrm{El}$ proceso de socialización política temprana (y el posterior) contiene un fuerte componente afectivo. Easton y Hess ya lo percibieron en

\footnotetext{
57 N. Bobbio y N. Matteucci, Diccionario de Política (Madrid: Siglo XXI, 1982), 1568.

58 Ver Gabriel Abraham Almond, «Introduction. A Functional Approach to Comparative Politics», en The Politics of the Developing Areas, eds. Gabriel Abraham Almond y James Smoot Coleman (New Jersey: Princeton University Press, 1960), 28; Robert E. Dowse y John A. Hughes, Political Sociology (London: John Wiley \& Sons, 1972), 182-189.

59 Gabriel Almond y Sidney Verba, The Civic Culture (Boston: Brown and Company, 1965).

${ }^{60}$ Ver David Easton y Robert D. Hess, "The child's political world'», Midwest Journal of Political Science VI, (3), (1962): 236. La cita original dice así: «The truly formative years of the maturing member of a political system would seem to be the years between the ages of three and thirteen».
} 
los años sesenta: «Como encontramos en la mayoría de los otros aspectos del mundo político del niño, y como era de esperar, sus respuestas están llenas de emoción y se producen mucho antes de que la comprensión racional o incluso la capacidad de racionalizar las orientaciones políticas sean evidentes». ${ }^{61}$

Los estudios sobre socialización política comenzaron a tomar fuerza a partir de la publicación de Hyman en 1959, al que siguieron los de Fred Greenstein y luego David Easton y Robert Hess, todos en la década de los sesenta. ${ }^{62}$ Estos autores entendían la socialización política como

El proceso de inducción en la cultura política. Su producto final es un conjunto de actitudes, cogniciones, estándares de valores y sentimientos hacia el sistema político, sus diferentes roles y poseedores de dichos papeles. También incluye un conocimiento de los valores que están afectando, y de los sentimientos hacia las entradas de las demandas y las reclamaciones en el sistema, y sus salidas autoritarias. $^{63}$

Es cierto, en definitiva, que la socialización política ha sido definida

en una amplia variedad de formas, aunque la variedad se reduce a dos alternativas principales. La definición más convencional implica el moldeamiento del niño por parte de la sociedad a algún modelo pre-establecido, por lo general uno que perpetua el status quo. Términos tales como "adoctrinamiento», «aculturación», «civilizador», «transmisión cultural», y «la adopción de las normas culturales» son sinónimos comunes para este uso. ${ }^{64}$

${ }^{61}$ Easton y Hess, «The child's political world», 236. «La cita original dice así: As we find in most other aspects of the child's political world, and as we would expect, their responses are highly coloured with emotion and occur long before rational understanding or even the capacity to rationalise political orientations are evident».

62 David O'Sears, «Political Socialization», en Handbook of Political Science, Vol. 2, eds. F. I. Greenstein y N. W. Polsby, (Reading M.A.: Addison-Wesley, 1975), 94.

${ }^{63}$ Almond, «Introduction», 28. La cita original dice así: «The process of induction into the political culture. Its end product is a set of attitudes, cognitions, value standards, and feelings toward the political system, its various roles and role incumbents. It also includes knowledge of values affecting, and feelings toward the inputs of demands and claims into the system, and its authoritative outputs».

${ }^{64}$ O'Sears, «Political Socialization», 95. La cita original dice así: «in a wide variety of ways, though the variety boils down to two main alternatives. The most conventional definition implies society's molding of the child to some a priori model, usually one perpetuating the status quo. Such terms as "indoctrination", "acculturation", "civilizing", "cultural transmission", and "adopting cultural norms" are common synonyms for this usage». 
O’Sears cuestionó la postura de los anteriores autores sobre la actitud positiva (idealización) de los niños ante su entorno político así como la importancia de estos primeros vínculos afectivos hacia lo político. ${ }^{65}$ Pero, en general, todas las definiciones coinciden en la naturaleza pedagógica de la socialización política, en tanto su mecanismo principal es un proceso de aprendizaje.

La socialización política y, según expresa Pierre Bourdieu, la propia acción política resulta posible porque es posible actuar sobre el mundo social actuando sobre las percepciones que los agentes sociales tienen de él, es decir, el cambio político presupone el cambio cognitivo. En esta conversión del conocimiento de los sujetos acerca del mundo social suelen estar presentes elementos constitutivos de una relación pedagógica.

La acción propiamente política es posible porque los agentes, que forman parte del mundo social, tienen un conocimiento (más o menos adecuado) de ese mundo y saben que se puede actuar sobre él actuando sobre el conocimiento que de él se tiene. Esta acción pretende producir e imponer representaciones (mentales, verbales, gráficas o teatrales) del mundo social capaces de actuar sobre él actuando sobre la representación que de él se hacen los agentes. $\mathrm{O}$, más concretamente, pretende hacer o deshacer los grupos $-\mathrm{y}$, al mismo tiempo, las acciones colectivas que esos grupos puedan emprender para transformar el mundo social de acuerdo con sus intereses-, produciendo, reproduciendo o destruyendo las representaciones que corporizan esos grupos y les hacen visibles para los demás. [...] la política comienza con la denuncia con este contrato tácito de adhesión al orden establecido que define la doxa originaria; dicho de otra manera, la subversión política presupone una subversión cognitiva, una reconversión de la visión del mundo. ${ }^{66}$

Dentro de la visión de la enseñanza y el aprendizaje de emociones y sentimientos, de su vinculación con la actividad cognitiva, de su dependencia de la comprensión del entorno y el contexto, y de su potencial para la acción social, defendemos la conceptualización de las emociones y los sentimientos como vías de canalización de las acciones del individuo y no solo como meras re-acciones. La emoción y el sentimiento tienen una dimensión más profunda

\footnotetext{
65 O’Sears, «Political Socialization», 95.

${ }^{66}$ P. Bourdieu, ¿Qué significa hablar? Economía de los intercambios lingüísticos (Madrid: Akal, 1985), 96.
} 
que la cadena mecánica y automática de estímulo/respuesta. La indignación, por ejemplo, es una reacción y una acción interna pensada, reflexionada ante una situación de abuso de poder, de injusticia, que puede o no tener una consecuencia social, como las «mareas» ciudadanas, las huelgas, las resistencias y los movimientos sociales. Éstos últimos ya no son objeto de análisis despectivos acerca de las masas y han comenzado - también desde los años noventa del siglo pasado- a ser examinados desde enfoques más comprensivos e inclusivos del papel desempeñado por las emociones en la construcción de identidades colectivas, en la comprensión de las protestas como oportunidades de motivar el activismo y de crear una sensación de comunidad dentro de los movimientos sociales. La movilización de afectos juega un papel importante en el proceso de convertirse en un participante del movimiento y de la cultura, rituales, trabajo y reglas emocionales de los movimientos sociales. ${ }^{67}$

Otra dirección relacional entre emociones y educación apunta hacia los metasentimientos de Castilla del Pino (como la vergüenza, la culpa y el remordimiento, «sentimientos de descontento sobre uno mismo», «sentimientos sobre sentimientos» o sentimientos provocados por otros sentimentos) y la autenticidad de los mismos: el teatro de la vida. Sentir vergüenza y malestar con uno mismo por sentir odio, por ejemplo. Pero claro, el niño y la niña pueden odiar a su padre o tener otras ideas políticas, pero no mostrarlo en el seno de la familia para evitar el castigo, el disgusto de sus padres, la humillación y la vergüenza social suya y de los suyos. En su intimidad tal vez sienta remordimientos (o no). El sujeto experimenta así una disociación obligada,

una disociación como si, porque no se vive como dos sujetos sino como uno capaz de doblez, capaz de actuar de dos maneras: una, para el espacio psicosocial, exterior; otra, para su reducto íntimo. Esta disociación es un peldaño importante en la sociabilidad. El sujeto tiene una doble vida, sigue la norma del grupo y ocultamente la transgrede. Esta doble vida a que hacemos referencia contribuye decisivamente al pacto social mediante esta hipocresía funcional. Por decirlo así, al sujeto se le permite que en su espacio íntimo piense y sienta lo que quiera que sea, con tal que actúe adecuadamente en las relaciones con los demás. El fairplay queda para las interacciones.

\footnotetext{
${ }^{67}$ Arlene Stein, «Revenge of the Shamed: The Christian Right's Emotional Culture War», en Passionate Politics. Emotions and Social Movements, eds. Jeff Goodwin, James M. Jasper y Francesca Polletta (Chicago, London: Chicago University Press, 2001), 117.
} 
Se le juzgará no por su intimidad, a la que solo él tiene acceso, sino por sus actuaciones públicas. ${ }^{68}$

La relevancia y trascendencia de las emociones y sentimientos enseñados y transmitidos tiene mayor repercusión educativa de la que a primera vista pudiera parecer; es decir, el aprendizaje emocional es mucho más complejo y profundo de lo planificado pues requiere un esfuerzo de introspección, lo que coincide en parte con la idea de Solomon sobre el grado de control (y autocontrol) sobre los sentimientos y sobre el aprendizaje de la teatralidad emocional: "Nuestras emociones no son sentimientos de los que somos víctimas; son más bien actuaciones teatrales en las que somos el actor principal y el director. Pero dicho esto, nosotros no escribimos la obra, sino que nos fue entregada por el conjunto de nuestra cultura». ${ }^{69}$

Desde el campo de la Historia de la Educación, en España podemos citar a algunos autores que se han ocupado de la socialización política aplicada a diversos periodos históricos, entre otros: Gregorio Cámara Villar (Nacional-Catolicismo y Escuela. La socialización política del franquismo, 1984); Alejandro Mayordomo y Juan Manuel Fernández-Soria (Vencer y convencer; educación y política: España 1936-1945; Patriotas y ciudadanos: el aprendizaje cívico y el proyecto de España, 1993), Juan Manuel Fernández-Soria (Educación, socialización y legitimación política, 1998).

\section{ENSEÑAR Y APRENDER EMOCIONES Y SENTIMIENTOS}

Desde la neurobiología, la sociología y otras disciplinas, la investigación ha tomado también una nueva dirección sobre la conexión entre la emoción y la razón, rompiendo con la tradicional dicotomía entre lo emocional y lo cognitivo. Los estudios de las emociones se abren camino dentro de la perspectiva biocultural y es aquí donde la educación entra en juego. Desde el momento en que se descubren las conexiones y los vínculos entre las emociones, las creencias, la moral, la ética, los valores y las acciones de las personas y de los grupos sociales, la educación puede plantearse analizar

\footnotetext{
${ }^{68}$ Carlos Castilla del Pino, Teoría de los sentimientos (Barcelona: Tusquets Editores, 2000), $143-144$.

69 Robert C. Solomon. Love. Emotion, Myth, \& Metaphor (New York: Prometheus Books, 1990), 41-52. La cita original dice así: "Our emotions are not feelings of which we are the victims; they are rather more like theatrical performances, in which we are both the leading actor and the director. But then again, we did not write the play, which has been handed down to us by the whole of our culture».
} 
detenidamente qué emociones transmite y enseña, las razones por las cuales lo hace de una determinada manera y no de otras igualmente posibles.

Nos decía Kant en su Pedagogía:

En educación, todo estriba en asentar por todas partes los principios justos y en hacerlos comprensibles y agradables a los niños. Han de aprender a sustituir el odio por el aborrecimiento de lo repugnante y absurdo; con el horror interior, el exterior de los hombres y castigos divinos; con la propia estimación y la dignidad interior, la opinión de los hombres; con el valor interno de la acción y la conducta, el de las palabras y movimientos del corazón; con el entendimiento, el sentimiento, y con una alegría y una piedad en el buen humor, la triste, tímida y sombría devoción. ${ }^{70}$

También en el siglo XIX, el filósofo y filántropo británico Charles Bray (1811-1884), creador del círculo Rosehill, ${ }^{71}$ fue uno de los autores que no solo analizó y estudió las emociones, sino que trató de forma específica la educación de las mismas. Publicó en 1836 una breve obra titulada The Educacion of the Body. An Address to the Working Classes. Dos años más tarde publicó The Education of the Feelings (1838). En la primera explicó por qué la educación comienza al nacer — no está restringida a la escuela- y trata del proceso que, con perseverancia, puede llevar a la máxima perfección - hasta lo que nuestra naturaleza lo permita - del cuerpo, los sentimientos, la mente y el intelecto. En la segunda obra definió la educación moral como «el cultivo por el ejercicio de esos sentimientos que nos hacen desear hacer lo que debemos hacer». ${ }^{72}$

En otras palabras, lo que «debemos hacer» nos lo enseña la educación intelectual, pero el mero conocimiento de lo que «debemos hacer» no es suficiente sin la adecuada disposición para hacerlo. Esta disposición se aprende a través de la educación moral, cuyo objeto es «frenar y dirigir los sentimientos egoístas, y cultivar y fortalecer la moral». ${ }^{73}$

\footnotetext{
${ }^{70}$ Kant, Pedagogía, 86.

${ }^{71}$ Círculo al que acudían diversas personalidades para realizar debates intelectuales. Entre los asistentes se encontraban Robert Owen, Herbert Spencer y más adelante Mary Anne Evans.

${ }^{72}$ Charles Bray, The education of the body, an address to the working classes (Coventry: Printed by Henry Merridew, 1836), 25. La cita original dice así: «the cultivation by exercise of those feelings which make us wish to do what we ought to do".

${ }^{73}$ Bray, The education of the body, p. 26. La cita original dice así: «to restrain and direct the selfish feelings, and to cultivate and strengthen the moral».
} 
La historia de la educación tiene un gran reto por delante en su contribución al estudio de las emociones y los sentimientos en los ideales, programas, procesos, contextos y materiales educativos de las diferentes épocas históricas. Advertía Rousseau en su Emilio:

Resulta extraño que, desde que se interviene en la educación de los niños, no se haya imaginado otro aparato para conducirlos que la emulación, los celos, la necesidad, la vanidad, la avidez, el vil temor, todas las pasiones más peligrosas, las más prontas a desbandadas, y las más a propósito para corromper el alma, incluso antes de que el cuerpo esté formado. A cada prescripción precoz que se intenta hacer entrar en su cerebro, se planta un vicio en el fondo de su corazón [...]. ${ }^{74}$

¿Qué pasiones —emociones y sentimientos- han estado presentes y formado parte de los programas educativos? ¿Han sido descuidadas? ¿Han sido protagonistas como objetivos y contenidos de las agendas políticoeducativas? Es sabido que han estado siempre presentes en la acción y relación pedagógica; a todos los niveles y no solo en la enseñanza primaria y secundaria. Hargreaves afirma de hecho que la enseñanza es una emotional practice. ${ }^{75}$ Mientras que las emociones de los maestros y profesores de primera y segunda enseñanza han sido ampliamente investigadas, las del profesorado universitario comienzan a tenerse en cuenta recientemente. ${ }^{76}$ Goleman incluyó un último capítulo titulado "Schooling the Emotions» en su libro Emotional Intelligence, afirmando la necesidad de incluirlas en la escuela. Entre los educadores contemporáneos algunos apoyan el curriculum emocional y otros critican que nos estamos alejando de estudios centrados en conocimientos sobre materias. ${ }^{77}$

Las emociones y la educación tienen una relación compleja y bidireccional. Por una parte, es a través de la educación formal y no formal como se conocen, familiarizan y adquieren numerosas emociones y sentimientos sociales. Este proceso permite la construcción de la identidad individual y

\footnotetext{
${ }^{74}$ Jean-Jacques Rousseau, Emilio o De la Educación (Madrid: EDAF, 1985 [1762]), 99.

${ }^{75}$ Andy Hargreaves, «The Emotional Practice of Teaching», Teaching and Teacher Education 14 (8), (1998): 835-854.

${ }^{76}$ Gerda Hagenauer y Simone Volet, «"I don't think I could, you know, just teach without any emotion”: exploring the nature and origin of university teachers' emotions», Research Papers in Education 29 (2), (publicado online: 02/01/2013; version impresa 2014): 240-262.

77 Thomas Dixon, «Educating the emotions from Gradgrind to Goleman», Research Papers in Education 27 (4), (2012): 482.
} 
colectiva - entendidas como dos niveles diferentes de auto-categorización igualmente válidos y expresiones auténticas del proceso psicológico del yo- ${ }^{78}$ y una subjetividad que hace posible la socialización del sujeto en sus diversos ámbitos. Aquí nos hallamos ante las emociones como un aspecto imbricado en las relaciones de poder en el campo educativo, pero no solo en el sentido que le otorga Joakim Landhal, ${ }^{79}$ el de comprender las relaciones de poder dentro de los contextos escolares, sino para comprender la perpetuación de las estrucutras de poder en la sociedad.

La investigación histórico-educativa contribuye a la construcción de la historia de las emociones con el rescate y examen de las emociones y los sentimientos presentes en los procesos, contextos y materiales educativos formales y no formales, así como de las estrategias empleadas en su transmisión y proyección (imposición, persuasión, recomendación,...). Es decir, analiza su presencia en la cultura material e inmaterial de la escuela, puesto que sus fuentes resultan pertinentes. Nutriéndonos de las aportaciones de otras ciencias, entendemos que no se trata exclusivamente de incluir programas de educación, gestión y conocimiento, competencia y alfabetización emocional, sino de hacer comprender a los estudiantes el papel que las emociones y los sentimientos han tenido y tienen - como elementos y variables explicativas - de la vida humana, de los fenómenos y hechos sociales y políticos. Aprender la relación existente entre lo afectivo, lo cognitivo, lo axiológico y la acción social puede conducir a moderar sentimientos de superioridad y generar emociones y sentimientos positivos y beneficiosos en lo social y político, como la solidaridad y la empatía. La incorporación de este conocimiento puede también ayudar a comprender el beneficio de un equilibrio emocional individual para el bien colectivo; que el nivel individual micro tiene repercusión en procesos colectivos macro ${ }^{80}$ Recordemos las palabras de Stuart Mill sobre las tres caras de la acción social:

Toda acción humana tiene tres aspectos: su aspecto moral, o su lado correcto o incorrecto; su aspecto estético, o aquel de su belleza; su aspecto comprensivo, o aquel de su amabilidad. El primero se dirige a la razón y la conciencia; el segundo a nuestra imaginación; y el

\footnotetext{
78 John C. Turner et al., «Self and Collective: Cognition and Social Context», Personality and Social Psychology Bulletin, PSPB 20 (5), (1994): 454.

79 Joakim Landhal, «Emotions, power and the advent of mass schooling», Paedagogica Historica, 51 (1-2), (2015): 104-116.

${ }^{80}$ Berezin, «Secure States: towards a political sociology of emotions», 35.
} 
tercero a nuestra afinidad humana. Según el primero, aprobamos o desaprobamos; según el segundo, admiramos o despreciamos; según el tercero, amamos, sentimos lástima o aversión. ${ }^{81}$

No es posible plantear la eliminación o supresión individual de las emociones «ruines» y «molestas» (celos, tristeza, odio, cólera, temor, rabia,...) al modo en que las dibujó Skinner en Walden Dos, ${ }^{82}$ pero sí saber detectarlas y conocer las consecuencias y el impacto de su experiencia, positivo (movilización social) y negativo (guerra), en los planos individual y colectivo. Siguiendo el pronóstico de Sobe, ${ }^{83}$ una de las grandes aportaciones de la historia de la educación puede ser una llamada de atención hacia la presencia y transmisión de determinadas emociones y sentimientos en los distintos contextos educativos a lo largo de la historia, programas y agendas político-educativas, y la necesidad de debatir sobre ellos para dilucidar cuáles y cómo se incorporan a lo educativo. Su inclusión o su exclusión afectará al pensamiento crítico, a la conciencia de uno mismo, a la percepción de la realidad; de la misma manera, el tipo de percepción y el grado de comprensión de la realidad - exigiendo una transmisión del conocimiento de calidad- dirigirá el sentimiento en una dirección u otra.

Kant pensaba que aunque las emociones pudiesen llevar algunas veces a hacer lo correcto creía que las acciones inspiradas en impulsos emocionales no podían ser auténticamente virtuosas. Si un hombre obedecía la ley por miedo no se estaría frente a un caso de conducta virtuosa. La única manera de obrar moralmente consistía en cumplir la ley moral de forma absolutamente no emocional, por pura obediencia a la ley. Esta concepción acarreó algunas consecuencias perniciosas, como el refuerzo de la concepción ne-

\footnotetext{
81 John Stuart Mill, «Bentham», en John Stuart Mill. Utilitarianism, On Liberty and Essay on Bentham together with selected writings of Jeremy Bentham and John Austin, editado con una introducción de Mary Warnock (Glasgow: Williams Collins Sons \& Co. Ltd, 1990, [20. ${ }^{\mathrm{a}}$ reimpresión, 1. ${ }^{\mathrm{a}}$ ed. 1962]), 121. Publicado originalmente en el London and Westminster Review, agosto 1838. La cita original dice así: «Every human action has three aspects: its moral aspect, or that of its right and wrong; its aesthetic aspect, or that of its beauty; its sympathetic aspect, or that of its loveableness. The first addresses itself to our reason and conscience; the second to our imagination; the third to our human fellow-feeling. According to the first, we approve or disapprove; according to the second, we admire or despise; according to the third, we love, pity, or dislike». Las cursivas son del autor.

82 B. F. Skinner, Walden Dos. Hacia una sociedad científicamente construida (Barcelona: Ediciones Martínez Roca, 1984, [1948]).

${ }^{83}$ Noah W. Sobe, "Researching emotion and affect in the history of education", History of Education 41 (5), (2012): 689-695. Disponible en http://dx.doi.org/10.1080/0046760X.2012.696150 (consultado el $17 / 09 / 2015)$
} 
gativa de las emociones, por un lado, y la concepción de la moralidad como un sistema objetivo de reglas a aplicar. El juicio moral consistiría en elegir la opción moralmente superior dentro de ese sistema general de reglas en cada caso particular. Esta concepción sería la modalidad predominante bajo la cual se enseñó ética en las escuelas, como un sistema mecanizado y automatizado de aplicación de reglas. Pero las facultades morales no se basan en un conjunto de instrucciones preprogramadas, «sino en emociones tales como la compasión, la culpabilidad o el orgullo [...] no es probable que podamos contribuir al desarrollo de las facultades morales de los niños inculcándoles mandamientos o preceptos, a menos que también se hayan cultivado debidamente sus capacidades emocionales». ${ }^{84}$

\section{EMOCIONES Y SENTIMIENTOS DESDE LA PERSPECTIVA DE LA HISTORIA DE LA EDUCACIÓN}

La temática principal de este monográfico tiene su origen en el proyecto de investigación "La dimensión afectiva de la socialización política. Emociones y sentimientos en los manuales escolares de la transición democrática española», ${ }^{85}$ dirigido por Miguel Somoza, con sede en el Centro de Investigación Manes ${ }^{86}$ y en el Departamento de Historia de la Educación y Educación Comparada de la Universidad Nacional de Educación a Distancia (UNED).

En ese sentido, una parte significativa de los artículos que se presentan toma como fuente principal de investigación los libros escolares y los procesos de transmisión de contenidos y valoraciones, a través de métodos didácticos y de prácticas materiales. Pero la atención principal se presta tanto a cuestiones políticas o públicas, de formación de mentalidades e imaginarios vinculados al ejercicio de la ciudadanía o al control social en general, como a cuestiones más próximas a un ámbito privado o íntimo ya sea la sexualidad o las creencias religiosas. Otra parte de los artículos aborda temas de socialización cultural y/o política que ocurre fuera de las instituciones escolares en diferentes momentos históricos.

\footnotetext{
${ }^{84}$ Dylan Evans, Emoción. La ciencia del sentimiento (Madrid: Taurus, 2002), 77.

${ }^{85}$ El Proyecto de investigación citado corresponde al Programa Nacional de Proyectos de Investigación Fundamental, en el marco del VI Programa Nacional de Investigación Científica, Desarrollo e Innovación Tecnológica, Subprograma de Proyectos de Investigación Fundamental no Orientada, EDU2012-32162. Más información en: http://servidormanes.uned.es/pemocw/

${ }^{86} \mathrm{http}: / / w w w . m a n e s . l i n h d . e s /$
} 
Es importante registrar que los artículos que toman los libros escolares como fuente principal fueron previamente presentados como comunicaciones en el XI Congreso Iberoamericano de Historia de la Educación Latinoamerica, realizado en Toluca, México, en 2014, como parte del panel «La construcción de las emociones a través de los textos escolares: estudio de casos de algunos países iberoamericanos», coordinado por Ana María Badanelli Rubio (UNED) y por Heloísa Helena Pimenta Rocha (UNICAMP), donde fueron debatidos y, posteriormente, revisados por sus autores. ${ }^{87}$

Volviendo al estudio de las emociones y los sentimientos, y preguntándonos acerca de su papel en los procesos de socialización que operan en diferentes sectores de la sociedad - y sobre todo, en la escuela-, los textos recogidos en este monográfico abarcan un amplio período histórico que va desde el siglo XVIII hasta el presente, con mayor énfasis en los siglos XIX y XX. La indagación que Alicia Villar Ezcurra realiza sobre la concepción antropológica postulada por Rousseau —basada en la bondad natural del hombre-, y la vinculación con el modelo educativo propuesto por el filósofo ginebrino, permite volver al siglo XVIII y retomar las ambivalencias frente al sentimiento de la compasión como fundamento de la moral, así como también frente a la oposición entre los sentimientos y la razón dentro de la historia del pensamiento occidental. Desde un punto de vista dirigido a la comprensión de la historia del tiempo presente, el análisis propuesto por María García indaga sobre las disputas entre los diferentes usos de la retórica emocional utilizada con el propósito de fortalecer los lazos de lealtad dentro de los sistemas políticos. Su artículo aborda las reformas educativas llevadas a cabo en España en tiempos presentes, entendidas como un contrapunto con las anteriores reformas implementadas en la década de 1930. Este análisis permite pensar en los cambios y continuidades de una retórica forjada sobre la apelación a las emociones como una forma de fortalecer modelos ideológicos, aún cuando estos fuesen de orientaciones políticas disímiles, formulados en las esferas del Estado, por una parte, y en las de la Iglesia católica, por otra.

La investigación realizada por María López sobre la construcción de una identidad lingüística en Argentina abarca un largo período que se extiende desde finales del siglo XIX hasta nuestros días, y nos permite comprender la lucha por el control de la lengua «legítima» y las tensiones suscitadas en-

${ }^{87}$ http://www2.cmq.edu.mx/gescon/index.php/cihela/cihela2014 
tre los sentimientos de orgullo/vergüenza y de superioridad/inferioridad en cuanto a la variedad lingüística local. Examinando los libros de texto que se producen en los 130 años de existencia del sistema educativo argentino, el análisis permite prestar atención a los cambios por los que pasa la práctica lingüística escolar, que va perdiendo sus lazos iniciales con un proyecto político destinado a la construcción de la identidad cultural de la nación y empieza a funcionar, ahora, en el contexto de las imposiciones del mercado. Las últimas décadas del siglo XIX y todo el siglo XX constituyen el marco temporal de los análisis llevados a cabo en los demás artículos.

Desde otra perspectiva, los textos que componen este monográfico permiten una aproximación a las disputas por el control de los proyectos de socialización en diferentes países, ampliando la investigación sobre las emociones y los sentimientos que se trató de activar dentro de los proyectos formulados en diferentes contextos sociales y en diferentes momentos históricos. Proyectos en los que entran en juego intereses políticos y económicos muy variados y, en algunos casos, directamente opuestos. El estudio de Ana Badanelli y Kira Mahamud se centra en el contexto educativo del tardofranquismo en España (1959-1975), prestando atención a las continuidades y a las novedades en los esquemas emocionales que se ponen de manifiesto en los libros de lectura producidos durante ese régimen político. La realidad española está contemplada, además, por María García Alonso, como ya se dijo, y también por Emilio Castillejo, quien centra su interés en comprender las inflexiones en los regímenes de gestión de los sentimientos de miedo por parte de la Iglesia católica española, tanto antes como después del Concilio Vaticano II (1962-1965).

Dirigiendo el enfoque hacia fuera del entorno escolar, el estudio realizado por Stephanie Olsen sobre las llamadas Bandas de la Esperanza, movimiento de educación informal que alcanzó su punto álgido en la década de 1910, dirigido a estimular la mesura y la contención entre las clases obreras, nos introduce en el contexto británico. Los países de América Latina también aparecen como un objeto de la investigación de los autores. La cuestión de la constitución de la figura materna y de la relación maternal, configurada como una relación amorosa entre madre e hijo, lleva a Federico Guillermo Serrano a un análisis que permite contrastar las formas en que esta relación estuvo presente en los libros de lectura producidos en la primera mitad del siglo XX en España y en Colombia. Por su parte, Pablo Toro examina los tópicos emocionales utilizados para la formación de un perfil deseable de 
alumno en un libro de lectura de amplia difusión, publicado entre los años 1933 y 1967, dirigido a los niños de la escuela primaria de Chile. Brasil está contemplado en la investigación de Heloísa Rocha, quien se interroga sobre la presencia y el papel de las emociones y sentimientos en los textos que abordan temáticas relacionados con la higiene y la salud, publicados entre los años 1920 y 1950, centrándose en la carga afectiva puesta en un proyecto de socialización que se afianza a través de distintos espacios institucionales y sociales, incluyendo la escuela.

Los autores utilizan, en sus investigaciones, un amplio y significativo conjunto de fuentes primarias, entre las que predominan los libros de texto, especialmente los de enseñanza de la lectura, analizados en conjunto con los respectivos curricula, programas educativos, revistas pedagógicas y otros textos. El artículo de Ana Badanelli y Kira Mahamud considera al libro de lectura como «vehículo privilegiado para la transmisión de conocimientos, valores y emociones en el tardofranquismo», indagando sobre los cambios estéticos, técnicos y didácticos de los libros de lectura puestos en relación con los cambios en los esquemas socio-emocionales trasmitidos. Los libros de lectura son también la fuente en la que se apoya Federico Serrano en su propósito por comprender los intentos de intervención en los afectos de los niños y en la configuración de los sujetos esposa, hijo e hija. Pablo Toro también se centra en el estudio de un libro de lectura, identificando en El niño chileno, obra que tuvo varias reediciones a lo largo de más de tres décadas, las huellas de un afán moralizante, lo que permite concebirla como un vehículo de valores políticos y culturales inmerso en un determinado proyecto de integración nacional. Heloísa Rocha hace uso de libros destinados, entre otras audiencias, a los niños que asistían a las escuelas primarias, examinando la dimensión afectiva presente en el tratamiento de las formas de prevenir la enfermedad y los — considerados por sus autores- excesos morales.

En el transcurso que va desde la constitución de la escuela como una agencia de construcción de ciudadanía a las iniciativas dirigidas al control lingüístico basado en las reglas del mercado, el estudio de María López elige como fuentes, además de los libros de texto, la legislación. Los manuales escolares de educación religiosa y de ciencias sociales conforman junto con documentos curriculares, cómics, boletines oficiales producidos por el Estado y otros materiales escolares, el corpus documental sobre el que María García examina las emociones relacionadas con la formación del sentimiento de ciudadanía. Los manuales de religión se combinan con 
los boletines oficiales eclesiásticos en el análisis que Emilio Castillejo hace sobre los usos políticos del miedo por parte de la Iglesia católica. La literatura infantil, los documentos producidos por las propias Bandas de la Esperanza, folletos y publicaciones periódicas son algunas de las fuentes examinadas por Stephanie Olsen en su intento de elucidar las estrategias de condicionamiento emocional puestas en marcha por una institución de educación informal. En el texto de Alicia Villar son las propias obras de Rousseau las que proporcionan el material para la investigación acerca de los sentimientos de bondad y compasión, y el lugar que ocupan o pueden ocupar en la educación moral.

A los artículos aquí reunidos hay que sumar las reseñas de obras que aportan referencias valiosas para el estudio de las emociones y los sentimientos, vinculados a los procesos de socialización, ya sea a través de la escuela o de otras instituciones educativas. Agustín Escolano reseña el trabajo de Stuart Walton, Humanidad. Una historia de las Emociones (2005), destacando, en su diálogo con el autor, la importancia de comprender la dimensión social de las emociones para poder comprender la historia de la humanidad, así como el papel de la escuela en la creación de estímulos emocionales. La discusión sobre las emociones y sentimientos que sustentan la vida en la sociedad adquiere relieve en la obra del primatólogo y etólogo Frans de Waal La edad de la empatía. Lecciones de la naturaleza para una sociedad más justa y solidaria (2011), cuya reseña fue escrita por Cecilia Milito. El legado biológico del linaje de los mamíferos es el eje que conduce el análisis del autor, como señala Milito, quien advierte, al mismo tiempo, sobre las posibles limitaciones de las tesis de Frans de Waal debido a la ausencia de un contexto social e histórico en sus análisis. El papel de las emociones en la creación y mejora de las instituciones, sustentadas en criterios de justicia, es el elemento central de la obra de Martha Nussbaum, Emociones politicas. ¿Por qué el amor es importante para la Justicia? (2014), según sostiene Virginia Guichot. El amor en general y, más específicamente, el amor a la patria o el patriotismo, a pesar de las dos caras que, como Jano, presenta, sería la mejor manera de contener las tendencias egoístas y garantizar el bienestar colectivo, pero para ello debe sortear cuatro peligros principales — que detalla- y fomentar una cultura pública crítica, inculcar el pensamiento reflexivo y el razonamiento ético en las escuelas.

El tema de la religión y de la moral religiosa se presenta en tres de las obras reseñadas. Las controversias que acompañaron el proceso de 
secularización constituyen el eje de las reflexiones propuestas por los autores de la obra Laicidade, religiões e educação na Europa do Sul no século XX (2013), editada por Joaquim Pintassilgo y reseñada por Paula Borges. Raimundo Cuesta presenta la obra autobiográfica de Francisco Pérez titulada Adiós a las almas (2012), que se inscribe en una corriente crítica con la Iglesia católica española, destacando las oportunidades que el trabajo ofrece para comprender las principales claves en la formación ideológica del clero español de la posguerra. Cuesta contribuye también con una revisión crítica de la biografía de José Ortega y Gasset (2014), de la autoría del catedrático de literatura española e historiador Jordi Gracia, que se incluye, como destaca Cuesta, en un tipo de narrativa en la que se articulan tanto las raíces identitarias como la ejemplaridad moral .

Amor a uno mismo, a la familia, a Dios, a la patria; bondad, compasión, piedad; sentido del deber, esperanza personal y colectiva; alegría, abnegación, empatía; odio a los enemigos y a los 'otros'; melancolía; miedo al pecado, al infierno, a los castigos, a las novedades, al desmoronamiento de la cultura, a las enfermedades y a la muerte; culpa, orgullo, vergüenza y sentimiento de inferioridad son objeto de la investigación de los textos que componen este monográfico. Constitución de la ciudadanía; construcción del sentimiento de maternidad y de responsabilidad por el mantenimiento de los lazos familiares asociado a la construcción de una identidad como mujer; preservación de la vida, prevención de los estados mórbidos, o el fortalecimiento de los sistemas políticos, figuran entre los objetivos de las investigaciones realizadas por los autores de los artículos. Patria, lengua, familia, maternidad, religión, enfermedad, vida y muerte, objetos inmersos en un complejo juego de emociones y sentimientos, son algunos de los ejes sobre los que se apoyan los análisis mencionados. Disputas, tensiones y ambigüedades; rupturas y permanencias en los regímenes socioemocionales puestos en funcionamiento, emergen junto a la pregunta sagaz de los autores sobre los usos políticos de las emociones y los sentimientos a través de agentes como el Estado, la iglesia, la escuela y las instituciones de educación no formal. En su conjunto, los textos contribuyen, creemos, a una nueva mirada sobre la Historia de la Educación que tenga en cuenta la dimensión emocional y sentimental que interviene en los procesos educativos tanto como las estrategias promovidas por los actores sociales y políticos en el arduo trabajo de constitución de las subjetividades. 